Article

\title{
Effect of Rare Earth Oxides on Microstructure and Corrosion Behavior of Laser-Cladding Coating on 316L Stainless Steel
}

\author{
Zezhou $\mathrm{Xu}^{1}{ }^{1}$, Zhiying Wang ${ }^{1, *}$, Jian Chen ${ }^{2, *}$, Yanxin Qiao ${ }^{2}{ }^{-}$, Junwei Zhang ${ }^{1,3}$ and \\ Yueming Huang ${ }^{1}$ \\ 1 School of Materials and Metallurgy, University of Science and Technology Liaoning, Anshan 114051, China; \\ X244282732@163.com (Z.X.); ustlzjw@163.com (J.Z.); huangyueming0626@163.com (Y.H.) \\ 2 School of Materials Science and Engineering, Jiangsu University of Science and Technology, \\ Zhenjiang 212003, China; yxqiao@just.edu.cn \\ 3 Laser Advanced Manufacturing Technology Center, University of Science and Technology Liaoning, \\ Anshan 114051, China \\ * Correspondence: wzhy74@163.com (Z.W.); jchen496@uwo.ca (J.C.)
}

Received: 23 September 2019; Accepted: 1 October 2019; Published: 2 October 2019

\begin{abstract}
The effect of rare earth oxides on the microstructure and corrosion behavior of laser-cladding coating on 316L stainless steel was investigated using hardness measurements, a polarization curve, electrochemical impedance spectroscopy (EIS), a salt spray test, X-ray diffraction, optical microscopy, and scanning electron microscopy (SEM). The results showed that the modification of rare earth oxides on the laser-cladding layer caused minor changes to its composition but refined the grains, leading to an increase in hardness. Electrochemical and salt spray studies indicated that the corrosion resistance of the 316L stainless steel could be improved by laser cladding, especially when rare earth oxides (i.e., $\mathrm{CeO}_{2}$ and $\mathrm{La}_{2} \mathrm{O}_{3}$ ) were added as a modifier.
\end{abstract}

Keywords: stainless steel; rare earth; laser cladding; corrosion

\section{Introduction}

As a popular and modern surface modification technique, laser cladding has many advantages, such as high metallurgical bonds with the substrate, few cracks and voids in the coating, and low energy input [1]. Rare earth oxides, some of the hottest modified materials used in the laser-cladding process, can not only optimize the microstructure and refine the grain, but can also improve fatigue, oxidation, wear, and corrosion resistance in various service environments [2-5]. This has resulted in laser cladding (using the modification of rare earth oxides) becoming a widely used coating preparation method [6-8].

Often, 316L stainless steel is used in marine environments, and it is a common manufacturing material for important ship components [9,10]. Nowadays, severe corrosion has been found on the materials used in the South China Sea region as a consequence of its unique atmosphere (i.e., high temperature, relative humidity, and UV light). For example, serious pitting corrosion has been observed on pipelines, which can lead to pipeline leakage and thus severe accidents. Specifically, high-pressure pipelines such as liquid hydrogen, gas supplies, and hydraulic pressure may cause serious accidents if corrosion occurs [11]. Thus, it is imperative to improve the corrosion resistance of the 316L stainless steel used in the South China Sea region. Presently, much research has been done to improve the corrosion resistance of 316L stainless steel. Dong et al. [12] reported that the corrosion resistance of 316 stainless steel could be increased by Ce element alloying at an optimal amount of $0.015 \mathrm{wt} \%$. The work conducted by Zhong et al. [13] showed that the formation of a Stellite-F 
alloy cladding layer on the surface of 316L stainless steel could improve its corrosion resistance. In addition, other works on the surface modification of other stainless steels (e.g., an Fe-based cladding layer on the surface of 35CrMo steel [14]) have shown that laser cladding enhances their corrosion and wear resistance [15-17]. Meanwhile, research regarding the effects of rare earth element alloying on the mechanical properties of materials has been performed. Liu et al. [18], who studied the effect of Ce alloying on the microstructure and mechanical properties of the $\mathrm{Fe}-\mathrm{Cr}-\mathrm{Al}$ alloy, found that the addition of Ce could greatly refine grain. When the Ce content reached $0.02 \mathrm{wt} \%$, the tensile strength and elongation of the $\mathrm{Fe}-\mathrm{Cr}-\mathrm{Al}$ alloy reached maximum values. Niu et al. [19] fused a cobalt-based powder modified by $\mathrm{CeO}_{2}$ onto the surface of $316 \mathrm{~L}$ stainless steel, and their results showed that the mechanical properties of the 316L stainless steel were the best when the additional content of $\mathrm{CeO}_{2}$ was $1.5 \mathrm{wt} \%$. Song et al. [20] also found that when La was added as a modifying agent and its content was $0.6 \mathrm{wt} \%$, the ADC12 alloy had the best inoculation effect and highest thermal crack resistance.

In the present paper, several new laser-cladding coatings on the surface of 316L stainless steel were developed: rare earth oxides were added to not only improve the mechanical properties of the laser-cladding coating by refining grain, but also to increase the corrosion performance in simulated marine environments. In comparison to corrosion behaviors in a series of electrochemical methods and corrosion tests, a more proper rare earth oxide for the surface modification of 316L stainless steel using laser cladding was determined.

\section{Experimental Methods}

\subsection{Preparation of Laser-Cladding Layer}

The material used was 316L stainless steel with dimensions of $150 \mathrm{~mm} \times 10 \mathrm{~mm} \times 8 \mathrm{~mm}$. The sample was cleaned with alcohol, mechanically polished using 200- and 600-mesh SiC paper, and finally rinsed with alcohol again. The powder used for laser cladding was 316 stainless steel powder with and without the addition of $2 \mathrm{wt} \% \mathrm{CeO}_{2}$ or $2 \mathrm{wt} \% \mathrm{La}_{2} \mathrm{O}_{3}$. After mechanical mixing, the average particle size of this mixed powder was $125 \pm 25 \mu \mathrm{m}$. The powder was then dried at $150{ }^{\circ} \mathrm{C}$ in an oven for $1 \mathrm{~h}$. The chemical composition of the 316L stainless steel powder was the same as that of the 316L bulk material to ensure a better metallurgical compatibility of the cladding layer with the bulk material, as shown in Table 1.

The cladding layer was prepared on the surface of the 316L stainless steel using an HGL-6000 $\mathrm{CO}_{2}$ gas-type laser. The diameter of the laser spot was $3.5 \mathrm{~mm}$, the laser power was $3000 \mathrm{~W}$, and the scan rate was $300 \mathrm{~mm} / \mathrm{min}$.

Table 1. 316L stainless steel composition (\% mass fraction).

\begin{tabular}{ccccccccc}
\hline Composition & $\mathbf{C}$ & $\mathbf{M n}$ & $\mathbf{P}$ & $\mathbf{S}$ & $\mathbf{S i}$ & $\mathbf{C r}$ & $\mathbf{N i}$ & $\mathbf{F e}$ \\
\hline Content & 0.03 & 1.3 & 0.006 & 0.006 & 0.46 & 16.06 & 10.01 & 72.128 \\
\hline
\end{tabular}

\subsection{Electrochemical Test and Surface Observation}

After laser cladding, the samples were cut into coupons with dimensions of $10 \mathrm{~mm} \times 10 \mathrm{~mm} \times 8 \mathrm{~mm}$ and then analyzed using a DX-2000 X-ray diffractometer (Palmer, Naco, Netherlands) to identify whether or not new phases formed in the laser-cladding coating. After the samples were etched with aqua regia, their microstructures were observed using a TK-C1381 metallographic microscope (Carl Zeiss, Bonn, Germany) and a Zeiss- $\Sigma$ IGMA HD field emission scanning electron microscope (SEM) from Carl Zeiss, Bonn, Germany.

The hardness measurements were performed on the cross-sections of the laser-cladding samples using an HVS-1000 digital microhardness tester with a load of $1000 \mathrm{~g}$ and a loading time of $5 \mathrm{~s}$. The interval of the measurement was $0.02 \mathrm{~mm}$.

The electrochemical corrosion behaviors of the 316L stainless steel with or without a laser-cladding coating were studied using an electrochemical workstation system. A three-electrode electrochemical 
system was employed with a saturated calomel electrode (SCE) as a reference electrode, a Pt plate electrode (surface area: $1 \mathrm{~cm}^{2}$ ) as a counterelectrode, and stainless steel samples as a working electrode. Prior to electrochemical tests, the sample was sealed using 704 silica gel with a total exposed surface area of $1 \mathrm{~cm}^{2}$, mechanically polished using 200-1200-mesh SiC paper, and then rinsed with water and alcohol. The corrosive medium used was $3.5 \mathrm{wt} \% \mathrm{NaCl}$ solution (prepared using $99.9 \%$ analytical-grade $\mathrm{NaCl}$ ). The temperature was room temperature, $\sim 25^{\circ} \mathrm{C}$, and the scan rate for the polarization curves was $0.167 \mathrm{mV} / \mathrm{s}$. After $3 \mathrm{~h}$ immersion in this solution, when the steady state was achieved, electrochemical impedance spectroscopy (EIS) measurements were performed over the frequency range $10^{5}-10^{-3} \mathrm{~Hz}$ using an electrochemical workstation. The validity of the impedance spectra was checked using the Kramers-Krönig transformation. A salt spray test was performed at $35 \pm 2{ }^{\circ} \mathrm{C}$ and $85 \%$ relative humidity using HDYW-100 composite salt fog, in which the $\mathrm{NaCl}$ concentration was $50 \pm 5 \mathrm{~g} / \mathrm{L}$ and the solution $\mathrm{pH}$ was $6.8 \pm 0.3$. The total exposure time for the salt spray test was $96 \mathrm{~h}$.

\section{Results and Discussion}

\subsection{XRD Analyses}

Figure 1 shows the XRD results of the cladding layer before and after the modification of different rare earth oxides. It is clearly shown that the addition of rare earth oxides did not change the phase composition of the cladding layer, which was mainly composed of an $\mathrm{Fe}-\mathrm{Cr}-\mathrm{Ni}-\mathrm{C}$ austenite phase. This indicates that the added rare earth should be present in the form of a solid solution state in the cladding layer, since the operation temperature of the laser cladding is far beyond the melting temperature of rare earth oxides (the melting temperature of $\mathrm{CeO}_{2}$ and $\mathrm{La}_{2} \mathrm{O}_{3}$ is $2400{ }^{\circ} \mathrm{C}$ and $2315{ }^{\circ} \mathrm{C}$, respectively, and the highest temperature of the spot center can reach about $2800^{\circ} \mathrm{C}$ with $3000 \mathrm{~W}$ of laser power [21]).

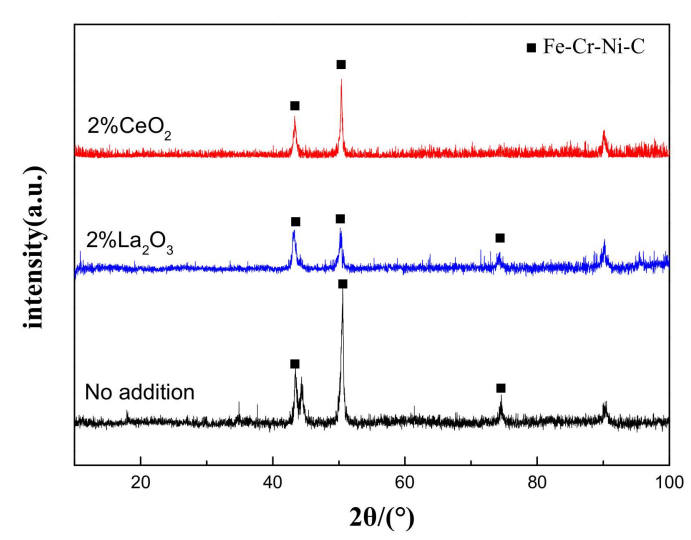

Figure 1. XRD patterns of laser-cladding layer on 316L stainless steel with or without the addition of rare earth oxides.

\subsection{Microstructure}

To characterize the quality of the laser-cladding layer, macroscopic cross-sections of the 316L cladding samples were cut, as shown in Figure 2. It is clear that there were three areas, identified as a coating zone, a heat-affected zone, and a 316L stainless steel substrate zone. The cladding layer was evenly distributed in the coating zone, without any pores, cracks, or other defects, suggesting that it formed a good metallurgical bond with the substrate. This was consistent with observations of the microscopic cross-sections of the laser-cladding 316L stainless steel samples using optical microscopy and SEM (Figures 3 and 4). Besides this, the grains of the cladding layer in the coating zone modified by rare earth oxides were refined (Figure $3 b, c)$ compared to those with no addition of rare earth oxides (Figure 3a), and grain refinement through $\mathrm{CeO}_{2}$ modification was better than that done through $\mathrm{La}_{2} \mathrm{O}_{3}$ 
modification. This might have been relevant to the involvement of rare earth in grain nucleation, crystallization, and growth.

The critical radius of grain nucleation, $r_{\mathrm{k}}$, can be defined as

$$
r_{\mathrm{k}}=\frac{2 \delta}{\Delta H}
$$

in which $\delta$ is the interfacial surface tension, and $\Delta H$ is the enthalpy change per unit volume.

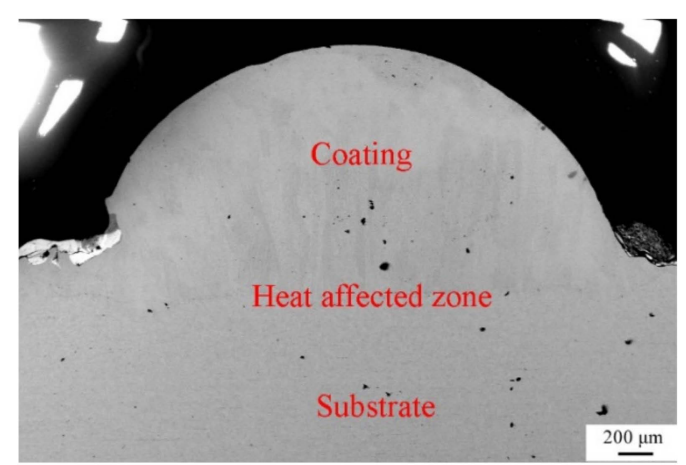

Figure 2. Photograph of cross-section of the laser-cladded 316L stainless steel modified using $2 \mathrm{wt} \% \mathrm{CeO}_{2}$.
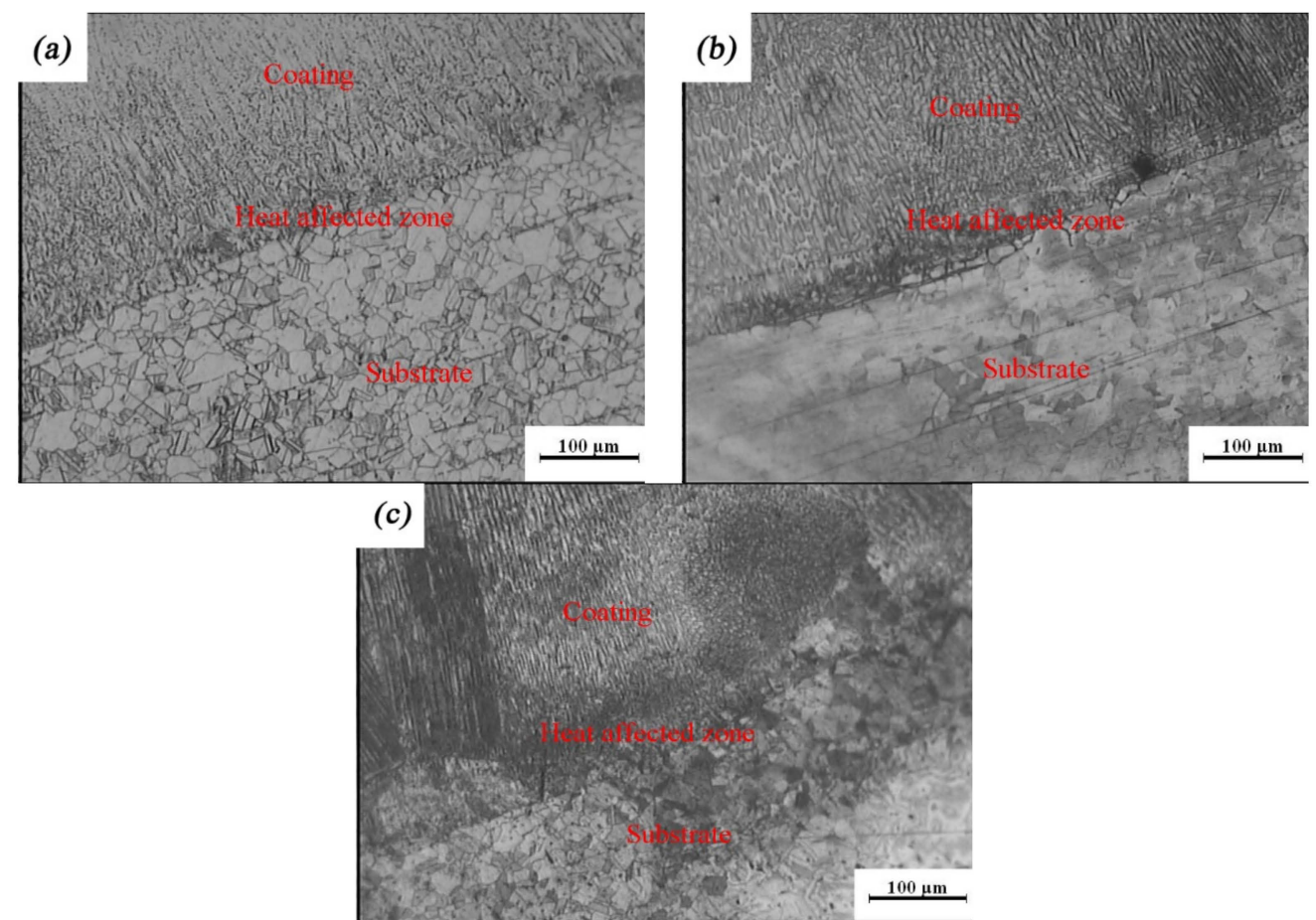

Figure 3. Optical images of rare earth oxide-modified 316L cladding layer: (a) no addition; (b) $2 \%$ $\mathrm{La}_{2} \mathrm{O}_{3} ;$ (c) $2 \% \mathrm{CeO}_{2}$. 

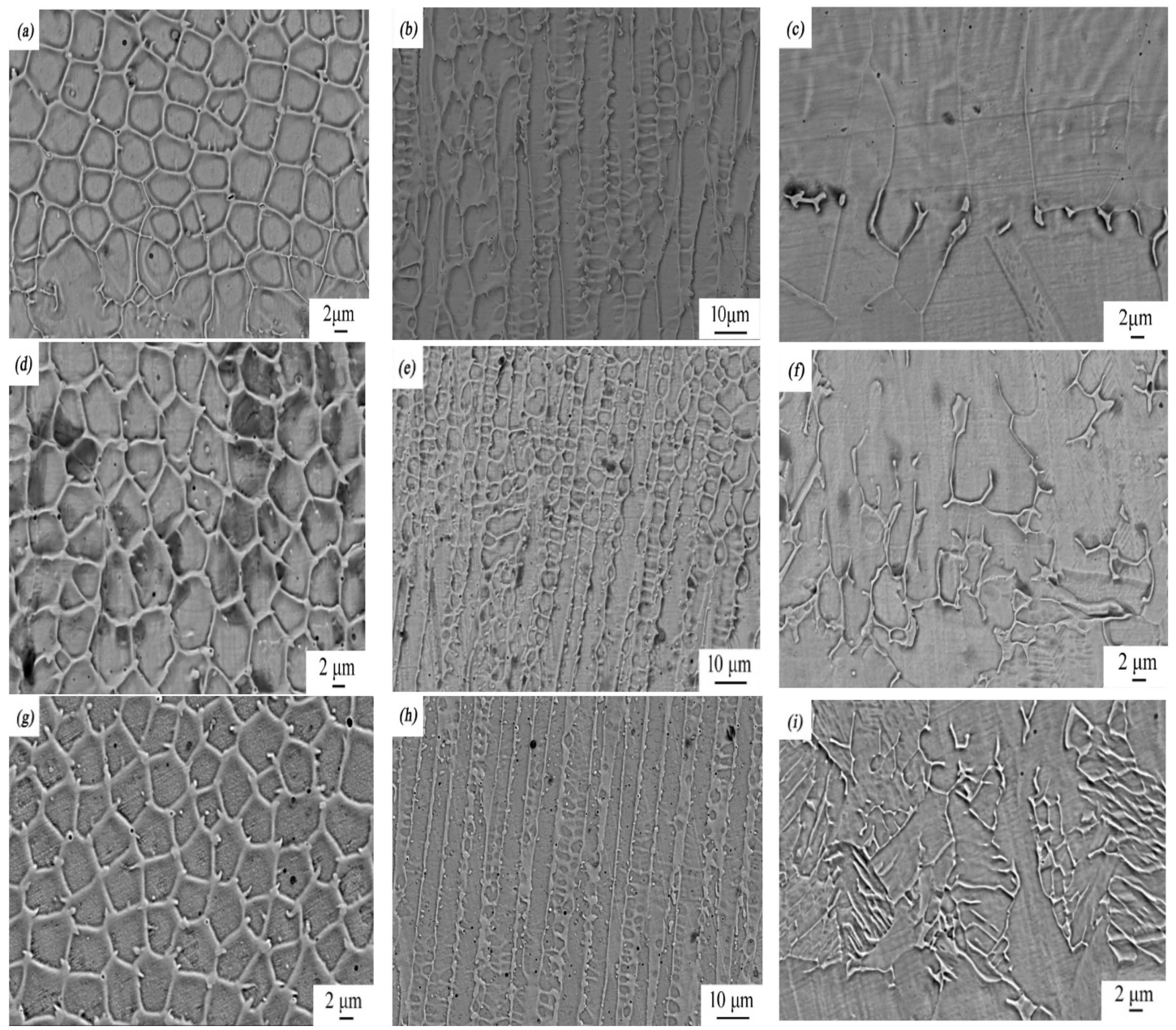

Figure 4. SEM micrographs of rare earth oxide-modified 316L cladding layer: (a) the top, (b) middle, and (c) bottom part of the laser-cladding layer when no rare earth was added; (d) the top, (e) middle, and (f) bottom part of the laser-cladding layer modified using $2 \mathrm{wt} \% \mathrm{La}_{2} \mathrm{O}_{3} ;(\mathrm{g}$ ) the top, (h) middle, and (i) bottom part of the laser-cladding layer modified using $2 \mathrm{wt} \% \mathrm{CeO}_{2}$.

Since the electronegativity of rare earth (i.e., Ce and La) is extremely strong [22], it could easily fill in the surface defects of the liquid metal alloy phase formed during laser cladding, and thus it decreased the interfacial surface tension, leading to a decrease in the critical grain nucleation radius and an increase in the crystal nucleus. On the other hand, the rapid condensation of laser cladding made the completion of grain crystallization rapid before the coarse growth of the grains, leading to grain refinement [23]. The solid-solution rare earth present in the cladding layer in the coating zone might also have contributed to this process.

Figure 4 shows the top, middle, and bottom images of the laser-cladding layer in the coating zone at higher magnifications using SEM. As the cooling rate of the laser-cladding layer during melting increased from the top to the bottom, its microstructure changed significantly, from equiaxed crystal to dendrite crystal to planar crystal. This phenomenon became prevailing when rare earth elements such as $\mathrm{Ce}$ and La were added and involved in this process. Compared to the sample with no modification of rare earth elements, grains of the samples with a modification of rare earth elements were greatly refined, especially when $\mathrm{CeO}_{2}$ was added.

After the laser cladding was applied, the microstructure of the cladding layer in the coating zone was dependent on the supercooling of the components at the solid-liquid interface frontier, the temperature gradient $(G)$, and the solidification rate $(R)$ in the liquid at the interface frontier [24]. The ratio of the temperature gradient to the solidification rate, $G / R$, was the largest at the interface of 
the melted laser-cladding layer and the 316L stainless steel substrate, decreasing successively toward the surface of the melted laser-cladding layer. The greater the $G / R$ was, the larger the supercooling rate was, which indicated that the supercooling rate at the interface of the melted cladding layer and the 316L stainless steel substrate was the largest, leading to the formation of a metastable phase at the interface (i.e., a plane crystal at the laser-cladding layer/316L stainless steel interface). When the supercooling rate continued to decrease, precipitates with a dendrite structure formed and grew. As the melting laser-cladding/air interface approached, the supercooling rate of the melted components continuously decreased, and new nuclei formed and grew as equiaxed crystals. Although the addition of rare earth oxides did not change the grain composition and arrangement in the laser-cladding process, it changed the grain size greatly. Since the atoms of rare earth elements have a large radius and their solubilities in the cladding layer are small, it is hard for XRD to detect them (Figure 1). However, the rare earth present in the form of a solid solution state accumulated at the grain boundary, inhibiting the recrystallization process by restricting grain growth and reducing secondary dendritic spacing, thus refining the grain.

\subsection{Hardness Measurements}

To ensure that the hardness of the laser-cladding layer did not change, hardness tests were performed from the coating zone to the 316L stainless steel substrate, as shown in Figure 5. It is obvious that the hardness of the laser-cladding layer increased, especially when rare earth oxides were added. The cross-sectional images of the laser-cladding samples in Figures 3 and 4 clearly show that the grain size decreased from the coating zone to the $316 \mathrm{~L}$ stainless steel substrate zone, which became common when $\mathrm{CeO}_{2}$ was added. Since the strength of a material is inversely dependent on its grain size [25] and hardness is directly proportional to strength [26], the hardness in the coating zone was higher than in other areas, especially when $\mathrm{CeO}_{2}$ was added (Figure 5).

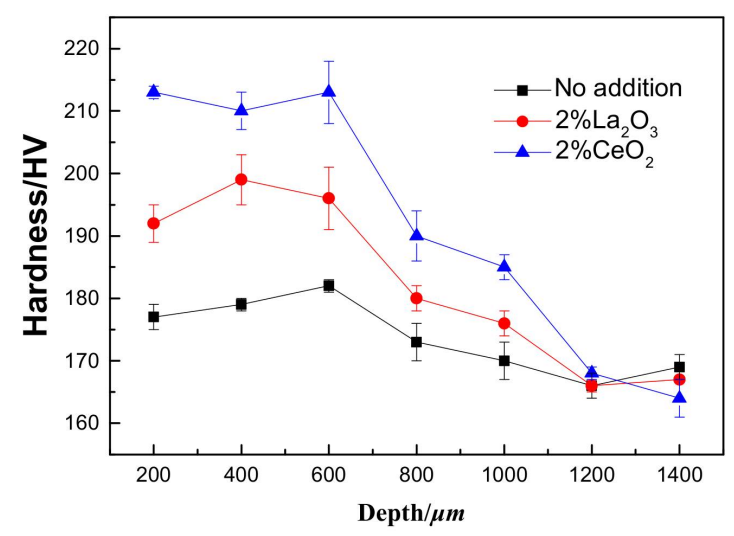

Figure 5. The hardness measurements of the laser-cladded 316L stainless steel with or without the modification of rare earth oxides from the laser-cladding coating zone to the $316 \mathrm{~L}$ stainless steel substrate zone. The measurement interval was $200 \mu \mathrm{m}$.

\subsection{Electrochemical Studies}

Figure 6 shows polarization curves of the 316L stainless steel before and after laser cladding with or without the modification of rare earth oxides in $3.5 \mathrm{wt} \% \mathrm{NaCl}$ solution. Compared to the $316 \mathrm{~L}$ stainless steel substrate, the corrosion potential positively shifted, and the passive current density decreased after laser cladding. The relevant parameters are shown in Table 2, which shows that laser cladding using rare earth oxide modification could significantly improve the uniform corrosion resistance of the 316L stainless steel in $3.5 \mathrm{wt} \% \mathrm{NaCl}$ solution. However, the decrease in pitting potential after rare earth oxide modification suggested that 316L stainless steel modified by laser cladding has a higher probability of undergoing pit corrosion in aerated $3.5 \mathrm{wt} \% \mathrm{NaCl}$ solution. 


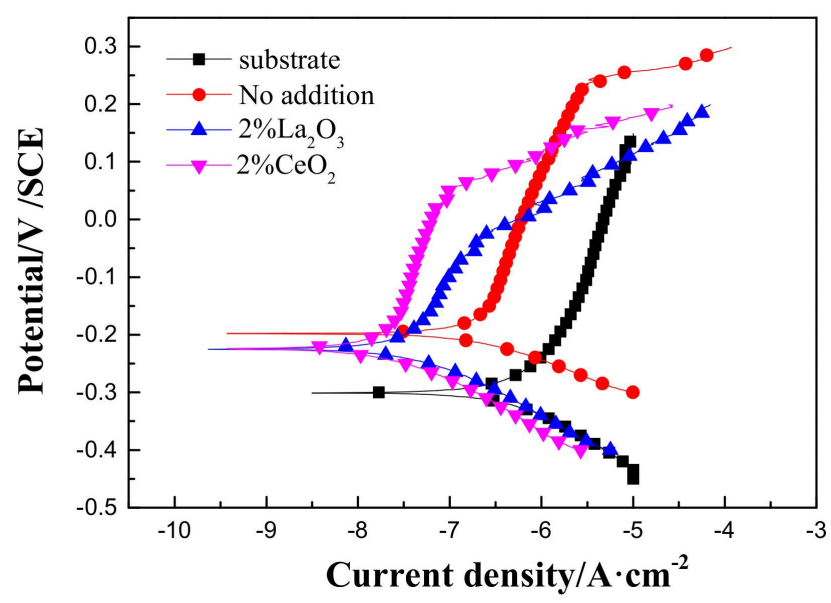

Figure 6. Polarization curves of 316L stainless steel before and after rare earth oxide-modified laser cladding in $3.5 \mathrm{wt} \% \mathrm{NaCl}$ solution.

Table 2. Electrochemical parameters of samples in $3.5 \mathrm{wt} \% \mathrm{NaCl}$ solution under different conditions.

\begin{tabular}{cccc}
\hline Coating & $\begin{array}{c}\text { Corrosion Potential } \\
\boldsymbol{E}_{\text {corr }} / \mathbf{V}\end{array}$ & $\begin{array}{c}\text { Current Density } \\
\boldsymbol{i}_{\text {corr }} / \boldsymbol{\mu A} \cdot \mathbf{c m}^{-2}\end{array}$ & $\begin{array}{c}\text { Pitting Potential } \\
\boldsymbol{E}_{\text {pit }} / \mathbf{V}\end{array}$ \\
\hline Substrate & -0.304 & 0.563 & $>0.2$ \\
Nothing added & -0.221 & 0.316 & 0.25 \\
$2 \% \mathrm{CeO}_{2}$ & -0.175 & 0.112 & 0.06 \\
$2 \% \mathrm{La}_{2} \mathrm{O}_{3}$ & -0.290 & 0.125 & 0.08 \\
\hline
\end{tabular}

After immersion in $3.5 \mathrm{wt} \% \mathrm{NaCl}$ solution for $3 \mathrm{~h}$, EIS was used to characterize the corrosion process of the 316L stainless steel with or without a laser-cladding layer, as shown in Figure 7. Generally, there was a single capacitive loop in the Nyquist diagram (Figure 7a) and a one-time constant in the Bode diagram (Figure $7 b, c)$. When rare earth oxides were added, the capacitive loop significantly increased, and the total resistance at the lowest frequency also increased, indicating that the corrosion resistance of the 316L stainless steel was improved by laser cladding, especially when $\mathrm{CeO}_{2}$ was added. Since passive film can easily form on the surface of 316L stainless steel [27-29], the equivalent circuit shown in Figure 8 was used to fit the EIS spectra, where $Q$ is the film capacitance, $R_{p}$ is the polarization resistance, and $R_{S}$ is the solution resistance. ZsimpWin V3.30 software was used for EIS spectra fitting, and the fitting dependency was $>90 \%$. The fitting results are shown in Table 3 . After laser cladding, the polarization resistance significantly increased. When $\mathrm{CeO}_{2}$ was added, the polarization resistance reached a maximum, $\sim 300 \mathrm{k} \Omega \cdot \mathrm{cm}^{2}$. This indicates that laser cladding improved the corrosion resistance as well as the hardness, and $\mathrm{CeO}_{2}$ modification could further help to increase the corrosion resistance of the cladding layer.

Table 3. Fitting parameters calculated by the equivalent circuit.

\begin{tabular}{ccccc}
\hline & Substrate & Nothing Added & $\mathbf{C e O}_{\mathbf{2}}$ & $\mathbf{L a}_{\mathbf{2}} \mathbf{O}_{\mathbf{3}}$ \\
\hline$R s / \Omega \cdot \mathrm{cm}^{2}$ & 6.218 & 6.877 & 4.896 & 5.501 \\
$R c t / \Omega \cdot \mathrm{cm}^{2}$ & 46,120 & 134,300 & 304,100 & 235,200 \\
$N$ & 0.8021 & 0.8089 & 0.8805 & 0.8642 \\
$Y_{0} / \Omega^{-1} \mathrm{~cm}^{2} \cdot \mathrm{s}^{-n}$ & $1.0818 \times 10^{-4}$ & $6.789 \times 10^{-5}$ & $3.509 \times 10^{-5}$ & $4.483 \times 10^{-5}$ \\
\hline
\end{tabular}


(a)

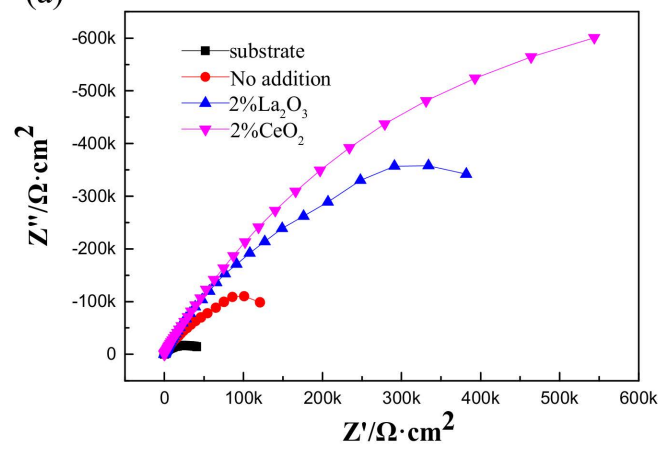

(b)

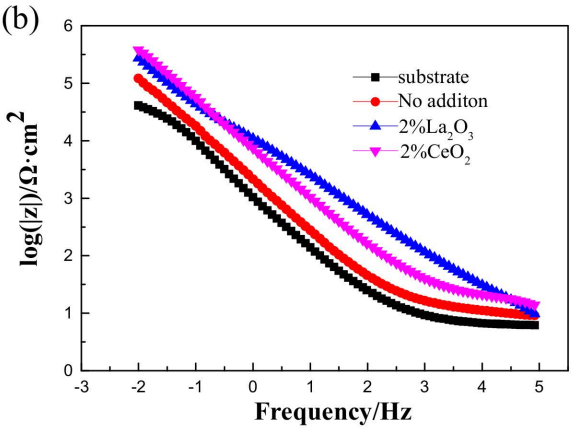

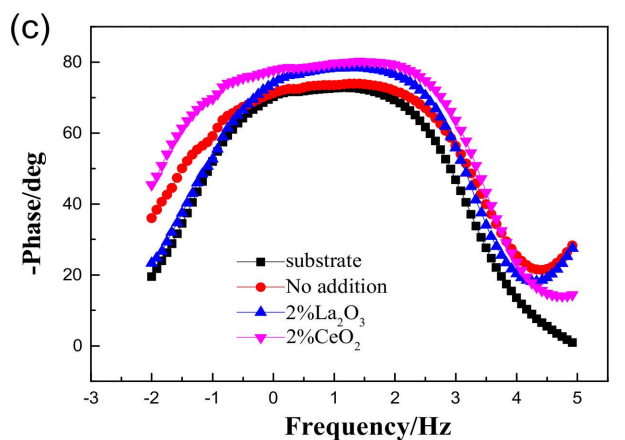

Figure 7. Electrochemical impedance spectroscopy (EIS) of 316L stainless steel before and after rare earth oxide-modified laser cladding in $3.5 \mathrm{wt} \% \mathrm{NaCl}$ solution: (a) Nyquist diagram; (b,c) Bode diagram.

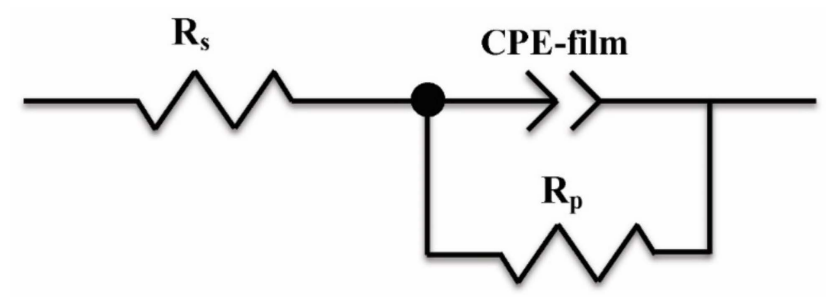

Figure 8. Equivalent circuit used to fit the EIS spectra.

\subsection{Salt Spray Tests}

Figure 9 shows the corrosion morphologies of the 316L stainless steel samples with and without laser-cladding coatings after a 96-h salt spray test in $\mathrm{NaCl}$ solution. Obviously, all of these four 316L stainless steel samples experienced pitting corrosion. Although the pitting events on and size of the laser-cladded 316L stainless steel modified using $\mathrm{CeO}_{2}$ were less than in the other three samples, the penetration depth of the pits could vary by the laser-cladding type. The differences in the pit nucleation and morphology might have been caused by grain refinement and/or the involvement of rare earth in the formation and repassivation of passive films on the 316L stainless steel $[15,30,31]$. 

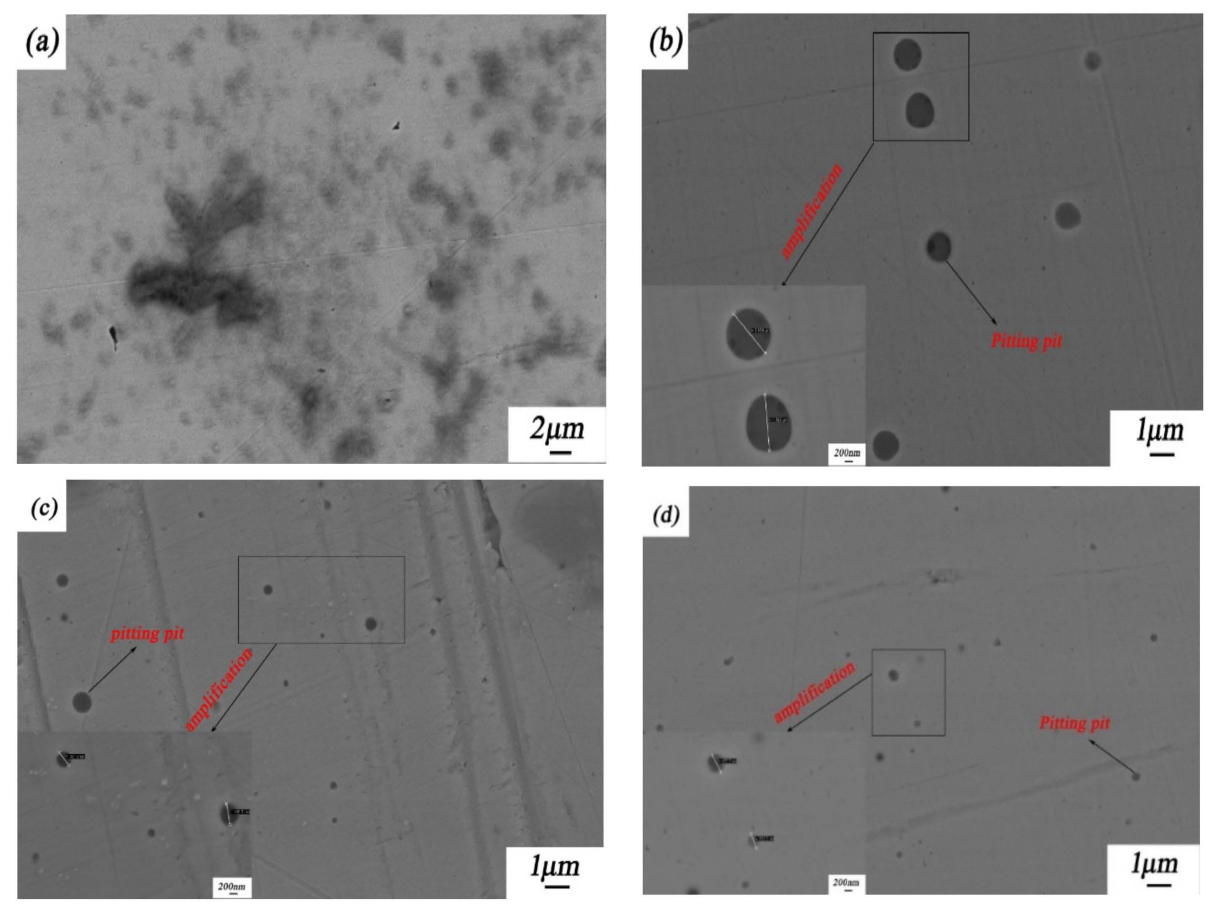

Figure 9. Corrosion morphologies of 316L stainless steel before and after rare earth oxide-modified laser cladding after a 96-h salt spray test: (a) 316L stainless steel substrate; (b) laser-cladded 316L stainless steel when no rare earth oxides were added; (c) laser-cladded 316L stainless steel modified using 2 wt \% $\mathrm{La}_{2} \mathrm{O}_{3}$; and (d) laser-cladded 316 L stainless steel modified using $2 \mathrm{wt} \% \mathrm{CeO}_{2}$. The average pit sizes in Figure $9 \mathrm{~b}-\mathrm{d}$ are 11182,426 , and $406 \mathrm{~nm}$, respectively.

\section{Conclusions}

Our conclusions are as follows:

- Laser cladding is a promising surface modification technique that can not only increase the strength and hardness of the surface coating of 316L stainless steel through grain refinement but can also improve its corrosion resistance in harsh environments such as concentrated $\mathrm{NaCl}$ solutions;

- The modification of rare earth oxides on a laser-cladding layer can further increase hardness and corrosion resistance, and a $\mathrm{CeO}_{2}$-modified laser-cladding layer is better than one that is $\mathrm{La}_{2} \mathrm{O}_{3}$-modified.

Author Contributions: Z.X. and Z.W. conceived of and designed the experiments; J.C. and Y.Q. are responsible for writing - review and editing, J.Z. provide methodology and materials, Z.X. and Y.H. analysis the data.

Funding: This research received no external funding.

Acknowledgments: Natural Science Foundation of Liaoning province (2015020226).

Conflicts of Interest: The authors declare no conflict of interest.

\section{References}

1. Mohseni, E.; Zalnezhad, E.; Bushroa, A.R. Comparative investigation on the adhesion of hydroxyapatite coating on Ti-6Al-4V implant. Int. J. Adhes. Adhes 2014, 48, 238-257. [CrossRef]

2. Wang, M.L.; Du, T.; Lu, X.L.; Le, K.X. Mechanism and application of trace rare earth elements in steel. Rare Earths 2001, 22, 37-40. [CrossRef]

3. Garrison, W.M.; Maloney, J.L. Lanthanum additions and the toughness of ultra-high strength steels and the determination of appropriate lanthanum additions. Mater. Sci. Eng. A 2005, 403, 299-310. [CrossRef]

4. Wang, L.M.; Lin, Q.; Yue, L.J;; Liu, L.; Guo, F.; Wang, F.M. Study of application of rare earth elements in advanced low alloy steels. J. Alloys Compd. 2008, 451, 534-537. [CrossRef] 
5. Xu, Z.Z.; Wang, Z.Y.; He, Z.J.; Zhang, J.W. Influence of laser power on microstructure and properties of laser cladding $\mathrm{CeO}_{2}$ modified 316L coating. Rare Metal 2019, 6, 18-23. [CrossRef]

6. Kim, S.T.; Jeon, S.H.; Lee, I.S.; Park, Y.S. Effects of rare earth metals addition on the resistance to pitting corrosion of super duplex stainless steel-Part 1. Corros. Sci. 2010, 52, 1897-1904. [CrossRef]

7. Zhang, H.; Zou, Y. Microstructure and properties of Fe-based composite coating by laser cladding Fe-Ti-V-Cr-C-CeO 2 powder. Opt. Laser Technol. 2015, 65, 119-125. [CrossRef]

8. Xing, H.; Dejun, K.; Renguo, S. Microstructures and properties of laser cladding Al-TiC-CeO ${ }_{2}$ composite coatings. Materials 2018, 11, 198. [CrossRef]

9. Jawwad, A.K.A.; Mahdi, M.; Alshabatat, N. The role of service-induced residual stresses in initiating and propagating stress corrosion cracking (SCC) in a 316 stainless steel pressure-relief-valve nozzle set. Eng. Fail. Anal. 2019, 105, 1229-1251. [CrossRef]

10. He, B.; Zhang, L.; Zhu, Q.; Wang, J.; Yun, X.; Luo, J.; Chen, Z. Effect of solution treated 316L layer fabricated by laser cladding on wear and corrosive wear resistance. Opt. Laser Technol. 2020, 121, 105788. [CrossRef]

11. Zhang, Y.; Liu, Y.; Li, K.; Tong, H.; Feng, C.; Zhang, H.; Wang, H. Study on pitting characteristics of 304 stainless steel in atmospheric environment of the South China Sea. Surf. Technol. 2018, 47, 44-50. (In Chinese)

12. Dong, H.Y.; Hu, L.J.; Liang, W.Y.; Xie, Y.P.; Lin, B.Q. Effect of rare earth Ce on corrosion resistance of 316L stainless steel. Corros. Sci. Prot. Technol. 2018, 30, 489-495. (In Chinese)

13. Zhong, X.K.; Wang, X.F.; Han, F.S. Electrochemical corrosion behavior of laser cladding stellite-F alloy layer on 316L stainless steel surface. Heat Treat. Metals 2019, 44, 176-179. (In Chinese)

14. Chen, J.; Zhou, Y.; Shi, C.; Mao, D. Microscopic analysis and electrochemical behavior of Fe-based coating produced by laser cladding. Metals 2017, 7, 435. [CrossRef]

15. Zhang, H.; Zou, Y.; Zou, Z.; Zou, Z.D.; Shi, C.W. Effects of $\mathrm{CeO}_{2}$ on microstructure and corrosion resistance of TiC-VC reinforced Fe-based laser cladding layers. J. Rare Earths 2014, 32, 1095-1100. [CrossRef]

16. Ye, S.Y.; Liu, J.Y.; Yang, W. Study on microstructure and properties of laser cladding 316L stainless steel coating. Surf. Technol. 2018, 47, 48-53. [CrossRef]

17. Cao, Y.L. Study on Microstructure and Properties of Laser Cladding Co/Rare Earth Coating on 316L Stainless Steel Surface. Ph.D. Thesis, Jilin University, Jilin, China, 2015.

18. Liu, N.M.; Zhang, Z.W.; Zhang, Y.; Cui, Y.; Chen, D.; Zhao, Y.; Xu, S.S.; Guo, H. Effects of Ce addition on the microstructure and mechanical properties of accident-tolerance $\mathrm{Fe}-\mathrm{Cr}$-Al fuel cladding materials. In Proceedings of the TMS Meeting \& Exhibition, Phoenix, AZ, USA, 11-15 March 2018; pp. 61-71. [CrossRef]

19. Niu, L.Y.; Cao, Y.L.; Tong, X.; Lin, J.X.; Li, G.Y.; Wang, W.Q. Effect of $\mathrm{CeO}_{2}$ on microstructure and corrosion resistance of laser cladding Co-based composite coating on 316L stainless steel. Appl. Laser 2015, 35, 304-308. [CrossRef]

20. Song, X.; Yan, H.; Chen, F. Impact of rare earth element la on microstructure and hot crack resistance of ADC12 alloy. J. Wuhan Univ. Technol. Mater. Sci. Ed. 2018, 33, 193-197. [CrossRef]

21. Zhao, Y.C.; He, W.; Zhang, J.R. Effect of laser power on temperature field of laser remelted cermet coating. Hot Work Technol. 2019, 48, 117-122. (In Chinese)

22. Fan, L.; Chen, H.Y.; Dong, Y.H.; Dong, L.H.; Yin, Y.S. Wear and corrosion resistance of laser-cladded Fe-based composite coatings on AISI 4130 steel. Int. J. Miner. Metall. Mater. 2018, 25, 716-728. [CrossRef]

23. Liu, X.B.; Yu, R.L. Effects of $\mathrm{La}_{2} \mathrm{O}_{3}$ on microstructure and wear properties of laser clad $\gamma / \mathrm{Cr}_{7} \mathrm{C}_{3} / \mathrm{TiC}$ composite coatings on TiAl intermatallic alloy. Mater. Chem. Phys. 2007, 101, 448-454. [CrossRef]

24. Li, C.F. Study on Corrosion Residual Strength of Rare Earth Ce Modified AZ91D Magnesium Alloy. Ph.D. Thesis, Jilin University, Jilin, China, 2010.

25. Zhou, S.F.; Dai, X.Q.; Zheng, H.Z. Microstructure and wear resistance of Fe-based WC coating by multi-track over-lapping laser induction hybrid rapid cladding. Opt. Laser Technol. 2012, 44, 190-197. [CrossRef]

26. Zhang, P.; Li, S.X.; Zhang, Z.F. General relationship between strength and hardness. Mater. Sci. Eng. A 2011, 529, 62-73. [CrossRef]

27. Abdulwahhab, Y.; Pojtanabuntoeng, T.; Kinsella, B.; Veder, J.P.; Barifcani, A. Comparison of corrosion behaviour and passive film properties of $316 \mathrm{~L}$ austenitic stainless steel in $\mathrm{CO}_{2}$ and $\mathrm{N}_{2}$ environments. Corros. Eng. Sci. Technol. 2019, 54, 10-21. [CrossRef]

28. Wang, Z.; Zhang, L.; Zhang, Z.R.; Lu, M.X. Combined effect of $\mathrm{pH}$ and $\mathrm{H}_{2} \mathrm{~S}$ on the structure of passive film formed on Type 316L stainless steel. Appl. Surf. Sci. 2018, 458, 686-699. [CrossRef] 
29. Xu, H.Z. Study on the Re-Passivation Behavior of 316L Stainless Steel and the Stability of Passivation Film. Ph.D. Thesis, University of Science and Technology Beijing, Beijing, China, 2016.

30. Zhao, T.; Cai, X.; Wang, S.X.; Zheng, S.A. Effect of $\mathrm{CeO}_{2}$ on microstructure and corrosive wear behavior of laser-cladded Ni/WC coating. Thin Solid Films 2000, 379, 128-132. [CrossRef]

31. Wei, M. Effect of Rare Earth Oxide $\mathrm{CeO}_{2}$ on Microstructure and Properties Of Laser-Clad Cobalt-Based Alloy of H13 Steel. Ph.D. Thesis, Harbin Institute of Technology, Harbin, China, 2018.

(C) 2019 by the authors. Licensee MDPI, Basel, Switzerland. This article is an open access article distributed under the terms and conditions of the Creative Commons Attribution (CC BY) license (http://creativecommons.org/licenses/by/4.0/). 